\title{
Maternofoetal Complications and Their Association with Proteinuria in a Tertiary Care Hospital of a Developing Country
}

\author{
Archana Kumari, ${ }^{1}$ Avinash Chakrawarty, ${ }^{2}$ Abha Singh, ${ }^{1}$ and Ritu Singh ${ }^{3}$ \\ ${ }^{1}$ Department of Obstetrics and Gynaecology, Lady Hardinge Medical College and Associated Hospitals, New Delhi 110001, India \\ ${ }^{2}$ Department of Medicine, All India Institute of Medical Sciences, New Delhi 110029, India \\ ${ }^{3}$ Department of Biochemistry, Lady Hardinge Medical college and Associated Hospitals, New Delhi 110001, India
}

Correspondence should be addressed to Avinash Chakrawarty; dravinashchak@gmail.com

Received 13 November 2013; Revised 20 February 2014; Accepted 20 February 2014; Published 14 April 2014

Academic Editor: Sinuhe Hahn

Copyright (C) 2014 Archana Kumari et al. This is an open access article distributed under the Creative Commons Attribution License, which permits unrestricted use, distribution, and reproduction in any medium, provided the original work is properly cited.

\begin{abstract}
Objective. To investigate association between maternofoetal complications and the amount of proteinuria measured by spot urine protein creatinine ratio in patients with preeclampsia. Methods. 200 consecutive patients with preeclampsia were recruited in the study. The complications like first episode of severe hypertension, renal insufficiency, raised level of aspartate transaminase, signs of neurological involvement, thrombocytopenia, eclampsia, and need to shift in intensive care units were studied. The maternal outcome was studied in terms of type of labour, outcome of pregnancy, mode of delivery, indication of cesarean section, and maternal mortality. The foetal complications and outcome parameters were birth weight, Apgar score at the time of birth and at five minutes, need of high dependency unit care, and perinatal mortality. Result. The frequency of various maternal and foetal complications was between $14-53 \%$ and $22-92 \%$, respectively. Maternal mortality was $3 \%$, whereas perinatal mortality was $23 \%$. Statistically significant association was found between the frequencies of various complications in mother and newborn and spot UPCR. Conclusion. The rate of various maternofoetal complications in preeclampsia is higher in developing countries than in developed world. Maternofoetal complications and outcome correlate with maternal spot UPCR.
\end{abstract}

\section{Introduction}

Preeclampsia is a major health problem in maternal health with the prevalence ranging from $1.8 \%$ to $16.7 \%$ in developing countries [1]. This multisystem disorder affects millions of women worldwide and is recognized as an important direct cause of maternal and foetal morbidity and mortality [2].

The course, prognosis, and outcome of this disease are quite heterogeneous and there exists great difference in the morbidity and outcome in the patients of developing and developed world. While there is lack of data from developing countries, studies from the developed world have reported complications in less than 10\% [3-5]. Recently, great interest has been shown by investigators all around the world to find out predictors/markers that can predict the maternofoetal outcome in patients with preeclampsia [6-8]. A couple of studies have also been done to find out association between the amount of proteinuria and maternofoetal outcome in patients with preeclampsia but the results have been variable [9-11].

At our centre, we have found relatively high prevalence of maternofoetal complications in patients with preeclampsia. This study was carried out in patients with preeclampsia to estimate the prevalence of maternal and foetal morbidity and to investigate the association between the amount of proteinuria measured by spot UPCR and maternofoetal outcome.

\section{Materials and Methods}

The study was approved by the Institutional Ethics Committee of Lady Hardinge Medical College on December 11, 2007, and written informed consent was taken in the approved format before enrolment of cases. This prospective observational study was done at the Department of Obstetrics 
and Gynaecology in collaboration with the Department of Biochemistry in Lady Hardinge Medical College and associated S.S.K. Hospital, New Delhi. 200 consecutive pregnant women with symptoms and signs suggestive of preeclampsia were enrolled from January 2008 to February 2010.

In the present study, preeclampsia was diagnosed in patients who had resting blood pressure equal to or more than $140 / 90 \mathrm{mmHg}$ at two different occasions at least 4 hours apart with significant proteinuria detected in urine samples (defined as more than or equal to $300 \mathrm{mg} / 24 \mathrm{hrs}$ or spot UPCR $0.3 \mathrm{gm} / \mathrm{gm}$ in random urine sample). We excluded patients with chronic hypertension, diabetes mellitus, preexisting renal disease, urinary tract infection, intrauterine foetal death, multiple-foetus gestations, premature rupture of membrane, and postterm pregnancy from our study. Postterm pregnancies were excluded from the study, as many of them needed urgent termination of pregnancy.

5-10 $\mathrm{mL}$ of voided midstream urine sample was collected for measurement of spot UPCR. Urine protein concentration was estimated on Synchron CX-9 automated analyser from Beckman, using the kits obtained from Randox. Urine creatinine concentration was measured by modified Jaffe's reaction which is based on the principle that creatinine in alkaline solution reacts with picric acid to form a coloured complex. The amount of colour formed is directly proportional to the creatinine concentration. The urine protein: creatinine ratio was calculated by dividing value of urine protein in $\mathrm{gm} / \mathrm{dL}$ by urine creatinine in $\mathrm{gm} / \mathrm{dL}$.

During the hospital stay, each patient was managed as per the standard protocol of the Institute. Blood pressure was checked every four to six hours and close monitoring was done for ominous clinical findings such as headache, visual problems, epigastric pain, rapid weight gain, oliguria, and vomiting. Fetal weight and amniotic fluid volume were evaluated. Doppler USG or biophysical scoring was done whenever indicated. Fluid input/output charting was done. All women in the study were followed until delivery and maternal and foetal complications were noted.

The maternal complications were studied in terms of (i) new episode of severe hypertension $(\geq 170 / 110 \mathrm{mmHg})$, (ii) renal insufficiency (serum creatinine $>1.2 \mathrm{mg} / \mathrm{dL}$ ) or oliguria $(<400 \mathrm{mg} / \mathrm{d})$, (iii) increased liver enzyme (AST $>40 \mathrm{U} / \mathrm{L}$ ), (iv) signs of neurological involvements (hyperreflexia with clonus), (v) presence of thrombocytopenia (platelet count $<$ $150 \times 10^{9} / \mathrm{L}$ ), (vi) episode of eclampsia, and (vii) need to shift in ICU.

The maternal outcome was studied in terms of (i) type of labour-spontaneous or induced, (ii) outcome of pregnancy-full term live birth or preterm live birth or intrauterine death, (iii) mode of delivery-normal or caesarean, (iv) indication of lower segment caesarean section (LSCS), and (v) maternal mortality.

The foetal complications and outcome parameters were (i) birth weight, (ii) Apgar score at birth and at 5 minutes, (iii) need for shift in HDU, and (iv) perinatal mortality.

Statistical Test. Independent $t$-test and one-way analysis of variance were used to find out association between spot UPCR and different maternal and foetal complications in
TABLE 1: General characteristics of the patients.

\begin{tabular}{llc}
\hline $\begin{array}{l}\text { Serial } \\
\text { number }\end{array}$ & Parameter & Value \\
\hline 1 & Mean age in years (S.D.) & $24.3(2.6)$ \\
2 & Primigravida : multigravida & $0.56: 1$ \\
3 & Mean period of gestation in weeks (S.D.) & $35.5(2.7)$ \\
4 & Diastolic blood pressure & \\
& (at the time of admission) & $38 \%$ \\
& $90-99 \mathrm{~mm}$ of Hg & $32 \%$ \\
& $101-109 \mathrm{~mm}$ of Hg & $30 \%$ \\
\hline
\end{tabular}

patients of preeclampsia. Multiple comparison tests were done by using bonferroni corrections. A $P$ value of $<0.05$ is considered to be statistically significant. Box and whisker plots were made to see the significant association between proteinuria and various complications.

\section{Results}

200 consecutive patients of preeclampsia were enrolled in the study. The general characteristics of the patients are mentioned in Table 1. The mean age of the patients was 24.3 years. More than two-thirds of the patients were multigravida. Almost one-third of the patients had severe hypertension on admission.

Table 2 shows the frequency of various maternal complications in the patients with preeclampsia and their relationship with the amount of proteinuria. Of the 200 hundred patients of preeclampsia, $44 \%$ developed severe hypertension, $21 \%$ developed raised liver enzymes, and 14\% developed renal insufficiency, whereas $23 \%$ of patients developed thrombocytopenia. $53 \%$ of the patients developed signs of neurological involvement (like hyperreflexia or clonus) and $31 \%$ of the patients developed eclampsia. The maternal mortality in our study was $3 \%$. The mean value of proteinuria was more statistically significant among the patients with complications like severe hypertension, raised liver enzymes, eclampsia, and need to shift in ICU. However, renal insufficiency, signs of neurological symptoms, thrombocytopenia, and maternal mortality showed no relationship with the amount of proteinuria.

Table 3 shows the outcome of labour in patients of preeclampsia and its association with the amount of proteinuria. $21 \%$ of the cases underwent spontaneous labour whereas in $79 \%$ induction of labour was done. $63 \%$ of the total patients delivered vaginally while $37 \%$ delivered by caesarean section. Of all the caesarean sections, more than $90 \%$ were emergency caesarean sections. A statistically significant association was found between the incidence of induced labour and amount of proteinuria present $(P$ value $=0.02)$. Caesarean section was also associated with high amount of proteinuria $(P$ value $=$ 0.01 ).

Table 4 shows the frequency of the various foetal complications and outcome in patients of preeclampsia and its association with the amount of proteinuria. Out of 200 
TABLE 2: Frequency of maternal complications and spot UPCR in the patients of preeclampsia.

\begin{tabular}{|c|c|c|c|c|c|c|}
\hline \multirow{2}{*}{$\begin{array}{l}\text { Serial } \\
\text { number }\end{array}$} & \multirow[b]{2}{*}{ Parameter } & \multicolumn{2}{|c|}{ Present } & \multicolumn{2}{|c|}{ Absent } & \multirow[b]{2}{*}{$P$ value } \\
\hline & & Number & $\begin{array}{c}\text { Proteinuria } \\
\text { spot UPCR } \\
\text { (gm/gm) }\end{array}$ & Number & $\begin{array}{c}\text { Proteinuria } \\
\text { spot UPCR } \\
\text { (gm/gm) }\end{array}$ & \\
\hline 1 & Severe hypertension & $88(44 \%)$ & $3.48 \pm 1.20$ & 112 & $1.86 \pm 0.90$ & 0.001 \\
\hline 2 & Raised liver enzymes & $42(21 \%)$ & $2.61 \pm 1.70$ & 158 & $2.12 \pm 1.10$ & 0.02 \\
\hline 3 & Renal insufficiency & $28(14 \%)$ & $2.42 \pm 1.93$ & 172 & $3.01 \pm 1.81$ & 0.12 \\
\hline 4 & $\begin{array}{l}\text { Signs of neurological involvement } \\
\text { (hyperreflexia or conus) }\end{array}$ & $106(53 \%)$ & $2.98 \pm 1.42$ & 94 & $2.76 \pm 1.31$ & 0.26 \\
\hline 5 & Thrombocytopenia & $46(23 \%)$ & $3.08 \pm 1.02$ & 154 & $2.88 \pm 0.94$ & 0.22 \\
\hline 6 & Eclampsia & $62(31 \%)$ & $3.92 \pm 2.31$ & 138 & $3.04 \pm 1.62$ & 0.002 \\
\hline 7 & Need to shift in ICU & $76(38 \%)$ & $2.98 \pm 1.53$ & 124 & $2.46 \pm 1.50$ & 0.02 \\
\hline 8 & Maternal mortality & $6(3 \%)$ & $2.69 \pm 1.11$ & 194 & $3.01 \pm 3.01$ & 0.45 \\
\hline
\end{tabular}

TABLE 3: Maternal outcome and spot UPCR in the patients of preeclampsia.

\begin{tabular}{|c|c|c|c|c|}
\hline & Parameters & Frequency & Proteinuria spot UPCR (gm/gm) & $P$ value \\
\hline \multirow{3}{*}{1} & Type of labour & & & \multirow{3}{*}{0.02} \\
\hline & Spontaneous & $42(21 \%)$ & $2.88 \pm 2.4$ & \\
\hline & Induced & $158(79 \%)$ & $3.98 \pm 2.75$ & \\
\hline \multirow{3}{*}{2} & Mode of delivery & & & \multirow{3}{*}{0.01} \\
\hline & Vaginal & $126(63 \%)$ & $2.84 \pm 1.9$ & \\
\hline & Caesarean & $74(37 \%)$ & $3.46 \pm 1.24$ & \\
\hline \multirow{4}{*}{3} & Outcome of labour & & & \multirow{4}{*}{0.001} \\
\hline & Full term live birth & $86(43 \%)$ & $2.14 \pm 1.05$ & \\
\hline & Preterm live birth & $88(44 \%)$ & $2.69 \pm 0.86^{\mathrm{a}}$ & \\
\hline & Intrauterine death & $26(13 \%)$ & $3.32 \pm 1.12^{\mathrm{b}, \mathrm{c}}$ & \\
\hline \multirow{3}{*}{4} & Indication of caesarean section & & & \\
\hline & Emergency caesarean section & $68(92 \%)$ & 3.86 & \multirow{2}{*}{0.002} \\
\hline & Elective caesarean section & $06(8 \%)$ & 3.38 & \\
\hline \multirow{2}{*}{5} & No Maternal mortality & $194(97 \%)$ & $3.01 \pm 3.01$ & \multirow{2}{*}{0.45} \\
\hline & Maternal mortality & $6(3 \%)$ & $2.69 \pm 1.11$ & \\
\hline
\end{tabular}

${ }^{\mathrm{a}}$ Comparison between full term live birth and preterm live birth ( $P$ Value: 0.001$) ;{ }^{\mathrm{b}}$ comparison between preterm live birth and intrauterine death $(P$ Value: $0.001){ }^{c}{ }^{c}$ comparison between full term live birth and intrauterine death $(P$ Value: 0.013$)$. Overall outcome of labour is significantly associated with proteinuria (one way analysis of variance).

TABLE 4: Fetal complications and outcome and spot UPCR in the patients of preeclampsia.

\begin{tabular}{|c|c|c|c|c|c|c|}
\hline \multirow{2}{*}{$\begin{array}{l}\text { Serial } \\
\text { number }\end{array}$} & \multirow[b]{2}{*}{ Parameters } & \multicolumn{2}{|c|}{ Present } & \multicolumn{2}{|c|}{ Absent } & \multirow[b]{2}{*}{$P$ value } \\
\hline & & Number & $\begin{array}{c}\text { Proteinuria } \\
\text { spot UPCR } \\
\text { (gm/gm) }\end{array}$ & Number & $\begin{array}{c}\text { Proteinuria } \\
\text { spot UPCR } \\
\text { (gm/gm) }\end{array}$ & \\
\hline \multirow{3}{*}{1} & Low birth weight & $128(71 \%)$ & $3.42 \pm 1.72$ & 46 & $2.82 \pm 1.51$ & 0.04 \\
\hline & Small for gestation age & $40(22 \%)$ & $3.08 \pm 1.20$ & 10 & $2.98 \pm 0.89$ & 0.81 \\
\hline & Prematurity & $88(49 \%)$ & $3.58 \pm 2.37$ & 36 & $2.63 \pm 1.41$ & 0.03 \\
\hline \multirow{3}{*}{2} & Low Apgar score & $166(92 \%)$ & $3.07 \pm 0.59$ & 08 & $2.64 \pm 0.08$ & 0.04 \\
\hline & At birth & $166(92 \%)$ & $3.75 \pm 1.25$ & 08 & $2.43 \pm 1.92$ & 0.005 \\
\hline & At 5 minutes & $116(64 \%)$ & $3.98 \pm 1.83$ & 58 & $2.65 \pm 1.75$ & 0.001 \\
\hline 3 & Need for shift in neonatal HDU & $96(53 \%)$ & $3.21 \pm 1.02$ & 78 & $2.87 \pm 0.98$ & 0.03 \\
\hline \multirow{3}{*}{4} & Perinatal mortality & $46(23 \%)$ & $3.80 \pm 2.27$ & 154 & $2.76 \pm 1.73$ & 0.001 \\
\hline & Still birth & $26(13 \%)$ & $3.40 \pm 1.23$ & 20 & $3.02 \pm 1.04$ & 0.27 \\
\hline & Early neonatal death & $20(10 \%)$ & $3.02 \pm 1.19$ & 26 & $3.40 \pm 1.23$ & 0.30 \\
\hline
\end{tabular}


deliveries, $26(13 \%)$ were still birth and $20(10 \%)$ were early neonatal death. Of the rest, $74 \%$ of newborns were born with low birth weight; two-thirds of them were premature. 58\% of newborns had to shift to neonatal HDU after birth. The perinatal mortality in our study was $23 \%$. Low birth weight (prematurity), need to shift in neonatal HDU, and perinatal mortality rate were found to be statistically significantly associated with high amount of proteinuria in mother.

Figure 1 shows the relationship between the numbers of maternal complications and amount of proteinuria (measured as spot UPCR as gm/gm) in the patients of preeclampsia. The diagram shows that progressive increase in amount of proteinuria is associated with increase in the number of complications.

Figure 2 shows the relationship between the numbers of fetal complications and amount of proteinuria (measured as spot UPCR as $\mathrm{gm} / \mathrm{gm}$ ) in the patients of preeclampsia. The diagram shows that progressive increase in amount of proteinuria is associated with increase in the number of complications.

\section{Discussions}

There has been considerable interest among researchers to find out the markers that can predict maternofoetal complications or outcome of labour in patients with preeclampsia. Several factors and candidate biomarkers have been studied that include blood cells, blood pressure measurement, maternal age, serum uric acid, and amount of protein and proteomics in urine $[6-8,12,13]$. The results have been variable in most of the studies. However, proteinuria estimation seems to be promising as a candidate biomarker in predicting maternal and foetal outcome in women with preeclampsia. In a nested case controlled study involving 946 patients from United Kingdom, women with preeclampsia and proteinuria (300-499 mg/24 h) were found to have higher complication rates than women with gestational hypertension and chronic hypertension without proteinuria. Adverse perinatal outcomes were also higher in the former group [14]. In another retrospective analysis of 670 patients done at a tertiary referral centre of Sydney (Australia), maternal and perinatal outcomes in proteinuric preeclampsia were compared with nonproteinuric hypertensive disease. In this, the proteinuric cohort had higher blood pressure, more frequent need of magnesium sulphate administration in the management, and more preterm and operative delivery. However, the perinatal mortality rate was lower in the babies of women with proteinuric preeclampsia in comparison with that of nonproteinuric women [15]. Yet in another systemic review of sixteen studies that involved 6749 women with preeclampsia it was found that amount of proteinuria is a poor predictor of either maternal or fetal complications [16]. In a study from UK, proteomics in urine were studied in 113 patients with preeclampsia of gestation periods $12-16,20$, and 28 weeks. Among these biomarkers like collagen alpha chain, fibrinogen alpha chain and uromodulin fragments were found to predict preeclampsia at gestational week 28 [17]. In another study proteomic profiling in urine samples from

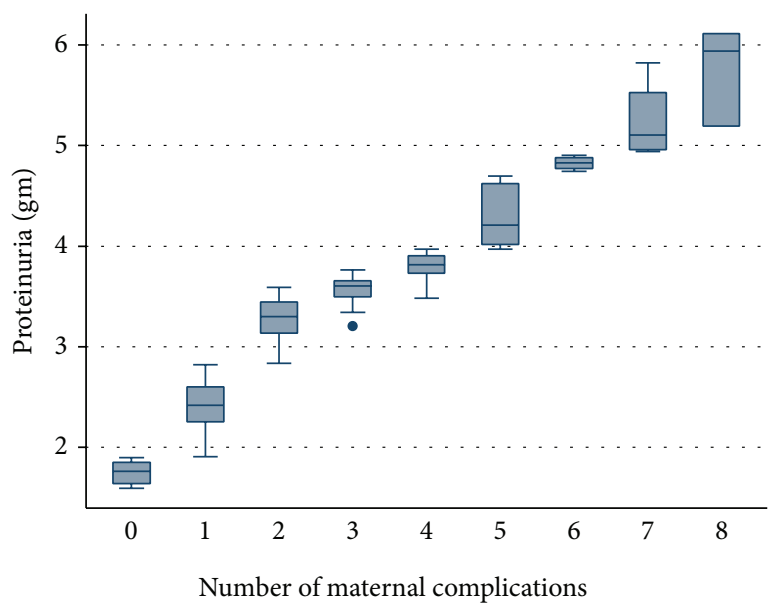

Figure 1: The relationship between the numbers of maternal complications and amount of proteinuria (measured as spot UPCR as $\mathrm{gm} / \mathrm{gm}$ ) in the patients of preeclampsia.

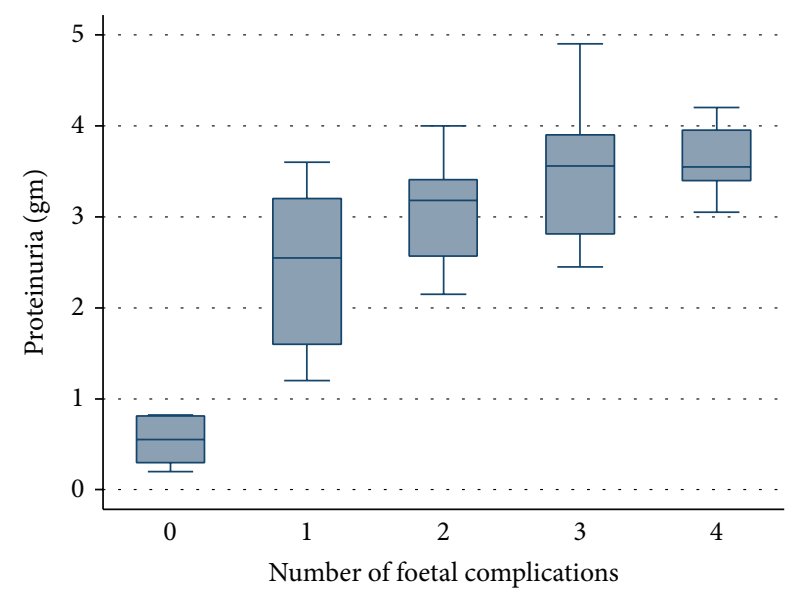

FIGURE 2: The relationship between the numbers of fetal complications and amount of proteinuria (measured as spot UPCR as $\mathrm{gm} / \mathrm{gm}$ ) in the patients of preeclampsia.

284 women was analyzed and it was identified that specific fragments of serpina- 1 and albumin have potential to be used as biomarkers of preeclampsia [18].

Although some of these studies suggest that patients with preeclampsia who had macroalbuminuria had poorer outcome, there is lack of consistency in predicting the different maternal and foetal outcome measures by measuring amount of proteinuria [10,13-16, 19]. Besides, most of these studies established the qualitative association; none investigated the quantitative association or strength of association between the two. This study was designed to investigate whether the frequency of various maternal and foetal complications is associated with the amount of proteinuria.

Majority of our patients were relatively young (mean age 24.3 years) and multigravida $(67.3 \%)$. The mean age of gestation at the time of presentation was 34.5 weeks. These findings are in accordance with the previous studies in which the mean age of gestation at the time of presentation 
was 34 weeks [19]. The prevalence of complications in our patients was high (up to $60 \%$ ). There is a paucity of studies from developing world and the studies from the developed countries suggest that the maternal complications among patients of preeclampsia are less than 10\% [3-5]. Frequencies of maternal complications like severe hypertension, raised liver enzymes, eclampsia, and need to shift in ICU were found to have statistical significant association with the amount of proteinuria in patients with preeclampsia. Though there is paucity of studies to investigate association between the individual complications, results of our study are in accordance with some of the previous studies in which proteinuria was associated with poor maternal outcome [10, 13-15, 20]. However, in some other studies measurement of proteinuria failed to predict the maternofoetal outcome $[7,11,16]$.

In our study, the prevalence of caesarean section was 37\%. We found statistically significant association between amount of proteinuria and caesarean section. Spontaneous labour was present in less than one-fourth of cases that underwent vaginal delivery. Majority of our patients had to undergo increased operative intervention, which was associated with the amount of proteinuria. Similar result was found in a couple of previous studies in which higher rate of caesarean section was observed $[15,19,21]$.

The foetal outcome was studied in terms of birth weight, Apgar score, and need to shift in neonatal HDU. In our study, $74 \%$ of newborns were of low birth weight; of these $70 \%$ were premature. The proportion of low birth weight and prematurity had statistically significant association with amount of protein in urine. $58 \%$ of newborns had to be shifted to neonatal HDU after birth. The perinatal mortality in our study was $23 \%$. These morbidity factors and perinatal mortality were significantly associated with maternal proteinuria. A couple of studies investigated association between maternal proteinuria and foetal outcome in patients of preeclampsia. In two of these studies, adverse foetal outcome was associated with amount of proteinuria $[9,19]$ whereas one study failed to establish any association between the two [21].

The limitation of our study was that it does not establish causal association, although it establishes significant association between amount of proteinuria and some of the maternofoetal morbidities.

Our study highlights two major findings. Firstly, the frequency of complications of preeclampsia in mother and foetus is significantly higher in our patients than what is mentioned in western literature. This can be because of other effect modifiers like nutritional deficiency, lack of awareness, late detection of complications and intervention, and so forth. Besides, there can be some genetic or racial factors that are not yet identified. Secondly, in our population, the frequencies of the maternofoetal morbidities were found to be associated with amount of proteinuria. Though there are a couple of studies that have similar findings, many of the studies including some of the systemic reviews have failed to find any association between maternofoetal outcome and proteinuria in patients of preeclampsia. The reason of the variation in the observation can be due to yet unidentified genetic or racial factors. Population based multicentric research is required in this part of the world to investigate this topic.

\section{Conclusion}

The prevalence of complications in mother and newborn was higher in our hospital based study. The maternofoetal complications and outcome of labour in preeclampsia were associated with maternal spot UPCR. Suitably designed cohort study is required to establish causal association.

\section{Ethical Approval}

The Ethical Committee of the Hospital approved the study on December 11, 2007, and informed consent was taken before enrolment of cases.

\section{Conflict of Interests}

The authors declare that there is no conflict of interests regarding the publication of this paper.

\section{Authors' Contribution}

Abha Singh and Archana Kumari designed the study. Archana Kumari and Ritu Singh did the collection of samples and biochemical analysis. Statistical analysis was done by Avinash Chakrawarty. All authors contributed to search, writing, and final approval of this paper.

\section{References}

[1] O. K. Osungbade and O. K. Ige, "Public heath perspectives of preeclampsia in developing countries: implication for health system strenghtening," Journal of Pregnancy, vol. 2011, Article ID 481095, 6 pages, 2011.

[2] R. A. Odegard, L. J. Vatten, S. T. Nilsen, K. A. Salvesen, and R. Austgulen, "Risk factors and clinical manifestations of preeclampsia," British Journal of Obstetrics and Gynaecology, vol. 107, no. 11, pp. 1410-1416, 2000.

[3] S. Bhattacharya and D. M. Campbell, "The incidence of severe complications of preeclampsia," Hypertension in Pregnancy, vol. 24, no. 2, pp. 181-190, 2005.

[4] P. von Dadelszen, B. Payne, J. Li et al., "Prediction of adverse maternal outcomes in pre-eclampsia: development and validation of the fullPIERS model," The Lancet, vol. 377, no. 9761, pp. 219-227, 2011.

[5] G. Yücesoy, S. Ozkan, H. Bodur et al., "Maternal and perinatal outcome in pregnancies complicated with hypertensive disorder of pregnancy: a seven year experience of a tertiary care center," Archives of Gynecology and Obstetrics, vol. 273, no. 1, pp. 43-49, 2005.

[6] S. Caritis, B. Sibai, J. Hauth et al., "Predictors of pre-eclampsia in women at high risk. National Institute of Child Health and Human Development Network of Maternal-Fetal Medicine Units," The American Journal of Obstetrics \& Gynecology, vol. 179, no. 4, pp. 946-951, 1998.

[7] S. Thangaratinam, K. M. K. Ismail, S. Sharp, A. Coomarasamy, and K. S. Khan, "Accuracy of serum uric acid in predicting 
complications of pre-eclampsia: a systematic review," An International Journal of Obstetrics and Gynaecology, vol. 113, no. 4, pp. 369-378, 2006.

[8] J. Sibiude, J. Guibourdenche, M. D. Dionne et al., "Placental growth factor for the prediction of adverse outcomes in patients with suspected preeclampsia or intrauterine growth restriction," PLoS ONE, vol. 7, no. 11, Article ID e50208, 2012.

[9] P. Chan, M. Brown, J. M. Simpson, and G. Davis, "Proteinuria in pre-eclampsia: how much matters?" An International Journal of Obstetrics and Gynaecology, vol. 112, no. 3, pp. 280-285, 2005.

[10] M. A. Brown and M. L. Buddle, "The importance of nonproteinuric hypertension in pregnancy," Hypertension in Pregnancy, vol. 14, no. 1, pp. 57-65, 1995.

[11] R. K. Morris, R. D. Riley, M. Doug, J. J. Deeks, and M. D. Kilby, "Diagnostic accuracy of spot urinary protein and albumin to creatinine ratios for detection of significant proteinuria or adverse pregnancy outcome in patients with suspected preeclampsia: systematic review and meta-analysis," The British Medical Journal, vol. 345, Article ID e4342, 2012.

[12] T. Tzur and E. Sheiner, "Is there an association between platelet count during the first trimester and preeclampsia or other obstetric complications later in pregnancy?" Hypertens Pregnancy, vol. 32, no. 1, pp. 74-82, 2013.

[13] M. A. Brown and M. L. Buddle, "Hypertension in pregnancy: maternal and fetal outcomes according to laboratory and clinical features," Medical Journal of Australia, vol. 165, no. 7, pp. 360-365, 1996.

[14] K. Bramham, C. E. Poli-de-Figueiredo, P. T. Seed et al., "Association of proteinuria threshold in pre-eclampsia with maternal and perinatal outcomes: a nested case control cohort of high risk women," PLoS ONE, vol. 8, no. 10, Article ID e76083.

[15] C. E. Thornton, A. Makris, R. F. Ogle, J. M. Tooher, and A. Hennessy, "Role of proteinuria in defining pre-eclampsia: clinical outcomes for women and babies," Clinical and Experimental Pharmacology and Physiology, vol. 37, no. 4, pp. 466-470, 2010.

[16] S. Thangaratinam, A. Coomarasamy, F. O’Mahony et al., "Estimation of proteinuria as a predictor of complications of preeclampsia: a systematic review," BMC Medicine, vol. 7, article 10, 2009.

[17] D. M. Carty, J. Siwy, J. E. Brennand et al., "Urinary proteomics for prediction of preeclampsia," Hypertension, vol. 57, no. 3, pp. 561-569, 2011.

[18] I. A. Buhimschi, G. Zhao, E. F. Funai et al., "Proteomic profiling of urine identifies specific fragments of SERPINA1 and albumin as biomarkers of preeclampsia," American Journal of Obstetrics and Gynecology, vol. 199, no. 5, pp. 551.el-551.e16, 2008.

[19] R. Gangaram, M. Naicker, and J. Moodley, "Accuracy of the spot urinary microalbumin:creatinine ratio and visual dipsticks in hypertensive pregnant women," European Journal of Obstetrics Gynecology and Reproductive Biology, vol. 144, no. 2, pp. 146$148,2009$.

[20] C. M. Liu, P. J. Cheng, and S. D. Chang, "Maternal complications and perinatal outcomes associated with gestational hypertension and severe preeclampsia in Taiwanese women," Journal of the Formosan Medical Association, vol. 107, no. 2, pp. 129-138, 2008.

[21] B. Srp, P. Velebil, and J. Kvasnička, "Lethal complications of preeclampsia and eclampsia," Ceska Gynekologie, vol. 67, no. 6, pp. 365-371, 2002. 


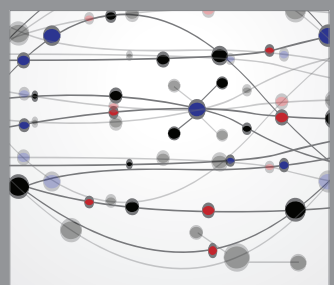

The Scientific World Journal
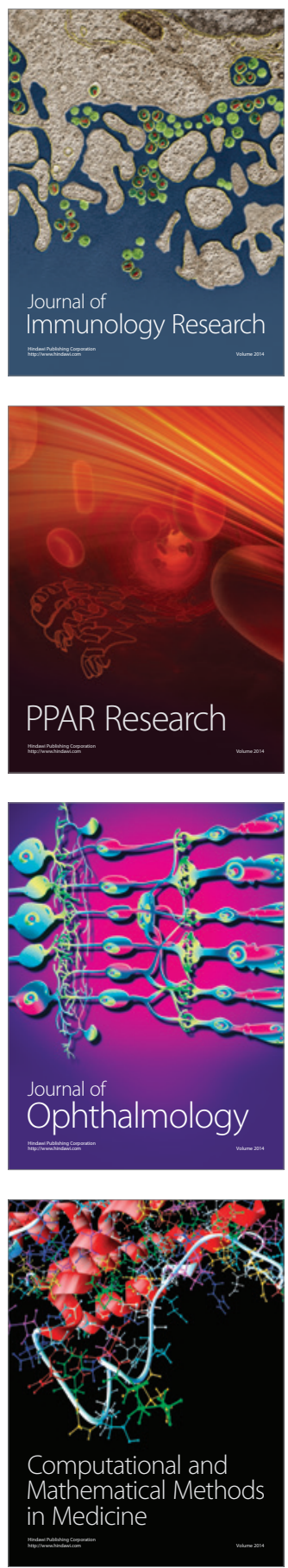

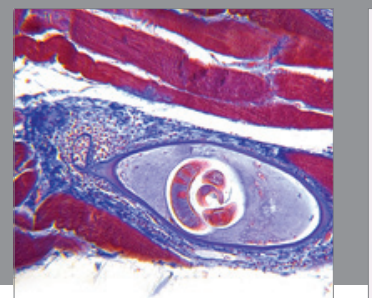

Gastroenterology

Research and Practice
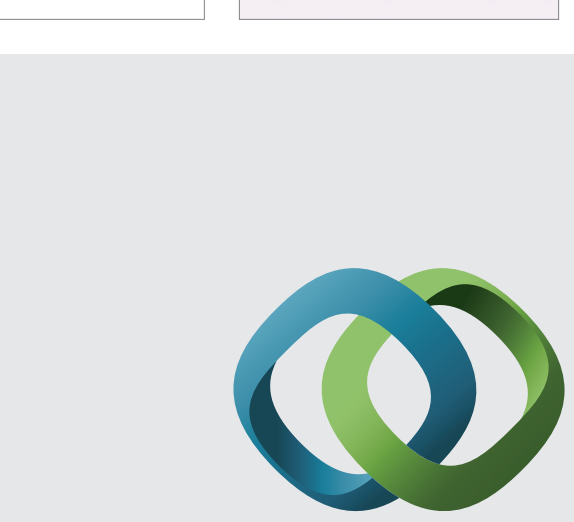

\section{Hindawi}

Submit your manuscripts at

http://www.hindawi.com
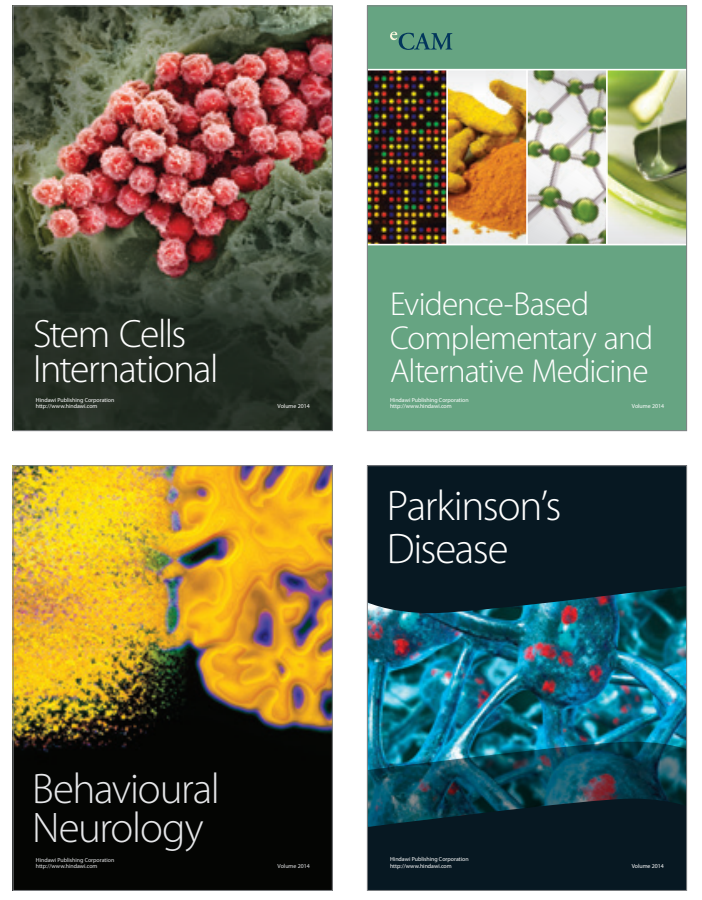
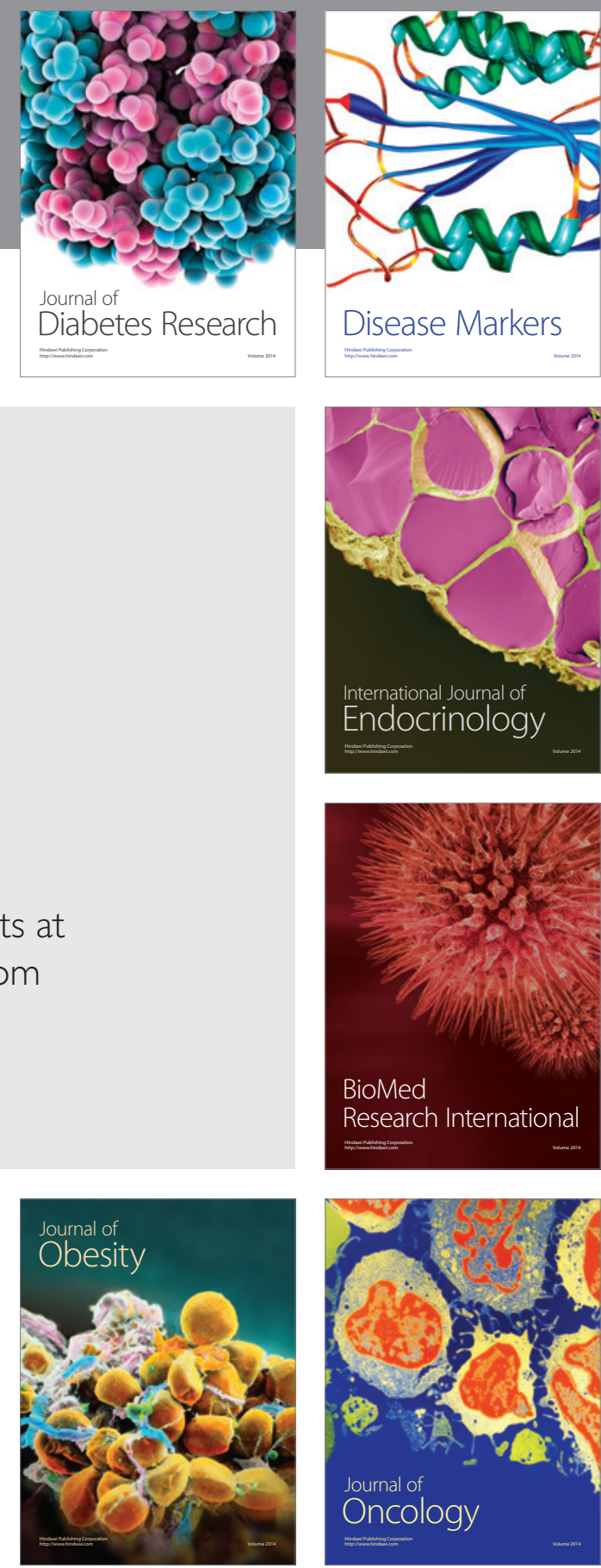

Disease Markers
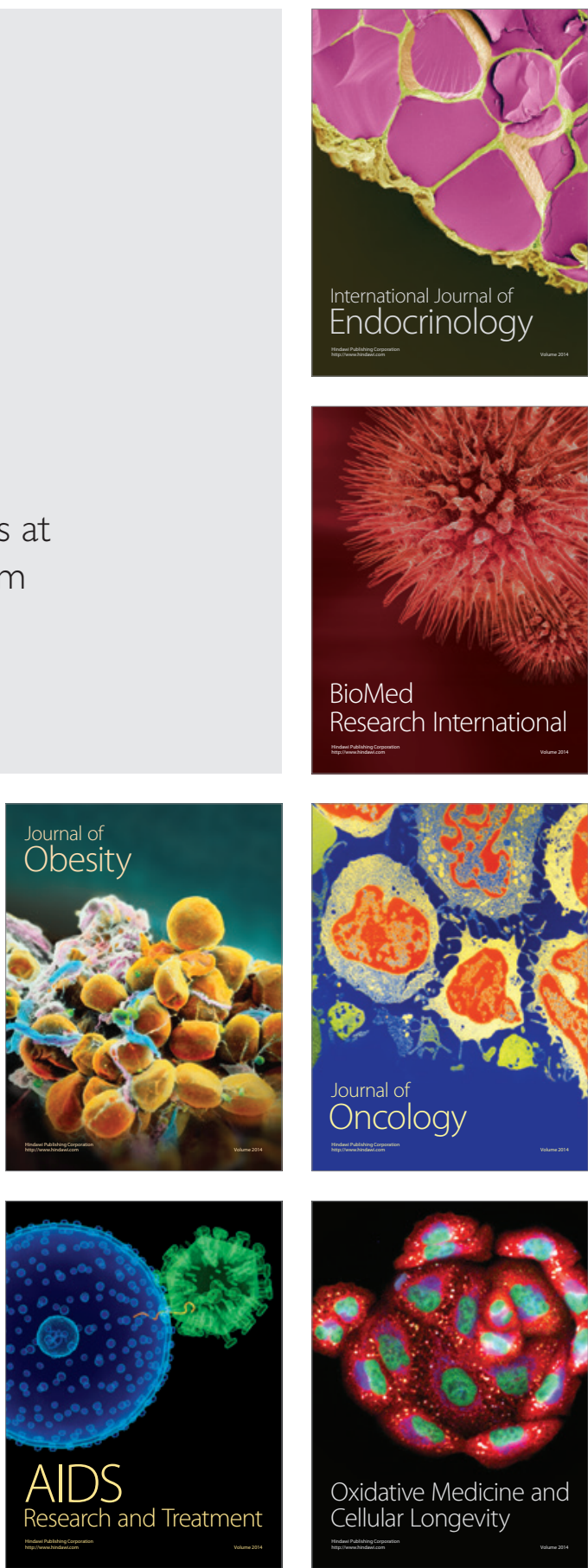